\title{
EXPLORING INTONATIONS IN SESAME STREET'S PUPPET SHOWS: A PHONOLOGICAL PERSPECTIVE
}

\author{
Ema Wilianti DEWI*1 \\ Nur Arifah DRAJATI ${ }^{2}$ \\ Melor M. YUNUS ${ }^{3}$ \\ 1,2 Universitas Sebelas Maret, Kota Surakarta, Jawa Tengah, Indonesia \\ ${ }^{3}$ University Kebangsaan Malaysia, Bangi, Selangor \\ 1emawiliantidewi@student.uns.ac.id \\ ${ }^{2}$ nurarifah_drajati@staff.uns.ac.id \\ 3melor@ukm.edu.my
}

Manuscript received 15 March 2019

Manuscript accepted 30 June 2019

*Corresponding author

10.33736/ils.1348.2019

\begin{abstract}
Intonation is a primary aspect in phonology, particularly in the supra-segmental area. Intonation carries meaning and changing the intonation of an utterance can quickly change the meaning of that utterance. This research aims to discover the patterns of intonation used in Sesame Street's puppet show and identify how interpersonal meaning is constructed on the show. This research was conducted from a phonology perspective and using the qualitative method. This research concentrates on phonology, mainly the supra-segmental area that is intonation. The focus of this study was on the relation between intonation patterns (tonality, tonicity, and tone) and interpersonal meaning. The website of Sesame Street was the source of Primary data for this study, as well as the puppet show's episode "Alphabet Race" (from Season 38). This research involved the researchers as its major instrument for analysing the data. In the process of collecting data, the researchers did documentation. This analysis finds the different division of the information between the systemic functional grammar level and the intonation level, which is shown from the clauses and tone units found in the show. The findings of this research provide teachers and EFL learners with further insight into how utterances deal with their intonation.
\end{abstract}

Keywords: intonation patterns, interpersonal meaning, phonology, suprasegmental, systemic functional linguistics 


\section{Introduction}

Teachers of spoken language, in classroom activities, may also have other aims. The teachers may not use their time only to teach speaking in the classroom, but also examine other aspects that support the study of speaking itself. As such, tasks that related to speaking may help students expand their awareness or practice facets of linguistic knowledge, develop productive skills (such as rhythm and intonation), or raise awareness of specific socio-linguistic or pragmatic considerations (Hughes, 2011). Spoken discourse not only uses rhythm as a source of productive skills in speaking but also intonation (Tench, 2011). There are six functions of English intonation: informational, grammatical, illocutionary, attitudinal, textual/discourse, and indexical (Couper-Kuhlen as cited in Chun, 2002). Ironically, intonation is often an overlooked aspect of speaking, and it is impossible to teach (Chun, 1998).

In EFL classrooms, intonation is often perceived as challenging to teach. Intonation is a particularly demanding aspect of L2 speech learning (Puga et al., 2017). Although teachers rarely notice the study and use of intonation, difficulties learning English can be overcome through EFL learners (Ali \& Yunus, 2014). Intonation patterns have a close relation to the interpersonal metafunction or meaning. The interpersonal meaning is one of the functions of tone (Tench, 2013). Interpersonal meaning expresses the feeling of the speakers and the reaction of the addressee. Interpersonal meaning has a close relation to the speaker's interaction in a conversation or the speech. Halliday (1994) argues that we enact our personal and social relationship with the other people around us when we inform or ask a question, give an order or make an offer, and express our appraisal of an attitude towards whoever we are addressing and what we are talking about. Thus, people always talk with interpersonal meaning to interact with other people. The interpersonal meaning can be seen from the intonational choices of the speakers when they speak.

This research focuses on the intonation that is the element of suprasegmental area of phonology. In conducting the research, the researchers need to provide some previous study to avoid the same or repeated study and also to recognize the position of this research. There is four previous research that is related to this present research: Liu (2008), Oladipupo (2010), Tuan (2012), and Onsuwan et al. (2014).

Liu (2008) investigated the different effects of two forms of focused instructional techniques on EFL learners' learning of English intonation. This research employs an experimental method and the place for doing the research was in University of Science and Technology, Beijing. The research results highlight the central role of instruction on intonation learning; the way of the teacher gives the instruction while learning intonation is also more efficient in intonation learning.

Oladipupo (2010) examined the English intonation patterns employed by Nigerian speakers of English for noun phrase in the subject's position and clause modifying adverbials, using forty Nigerian television reporters as research subjects. The analysis took data from reports broadcast on air and found an $89.3 \%$ tonal rise on noun phrase in the subject's position and $87.9 \%$ tonal rise in clause modifying adverbials. 
Tuan (2012) examined the reasons for intonation being ignored in pronunciation teaching at Ho Chi Minh City University for Natural Resources and Environment (HCMUNRE) and corroborated that teaching intonation in Yes/No questions and $\mathrm{WH}$-questions to learners has a positive influence on their Englishspeaking skills. The results found that a good number of teacher and students know that intonation is an essential aspect of communication. Unfortunately, they have no motivation to teach or learn intonation because it is not included in final exams.

Onsuwan et al. (2014) investigated Thai children's production and perception of tones acquired from a puppet show. Using the experimental method, they found that there seemed to be a negligible difference in the production of children pronunciation. The study encouraged the researchers to have the more indepth research on the intonation of puppet show and the relation between the intonation and interpersonal meaning of the puppet show. Jamin (2003) found that puppeteers will be assessed on the speaking voices with regards to express ideas in an entertaining or informative manner, how loudly or softly they speak, how they express things in words (language use/word choice), and how they use intonation (the rise and fall in pitch of the voice in speech). Despite the importance of content accuracy and speaking voices of the puppeteers, few researchers have analyzed the pattern of those speaking voices. The intonation pattern is a crucial part of speech, as, from intonation, we can assume meaning and perception. Intonation also works on the feelings a person deals with. The research question addressed in this study was what pattern of intonation is used in Sesame Street's puppet show and how the intonational choices constructed interpersonal meaning in the show. Therefore, this study aimed to explore the intonation patterns used in Sesame Street's puppet show and to identify how intonational choices in the show construct interpersonal meaning.

\section{Literature Review}

\section{Intonation Patterns}

In everyday life, when people speak or write, they produce text. The word 'text' refers to any instance of language, in any medium, that makes sense to someone who knows the language (cf. Halliday and Hasan, 1997: Chapter 1, as cited in Halliday, 2004). To seek a comprehensive view of English grammar, the phonological aspects have to be explored. This is because some grammatical systems are realized by prosodic means (Halliday, 2004).

There will always be various ways of intoning an utterance when a text is presented in writing, each of which will carry a different meaning, but only a small number of possible intonation patterns will appear more natural (Halliday, 2004). Intonation has three primary systems: tonality, tonicity, and tone (Tench, 2011). Tonality is the partition of spoken discourse into discrete units of intonation, each of which carries a piece of information (Tench, 2011). This can easily be demonstrated by listening to the same sentence spoken with different tonalities. As such, we convey much information in chunks, also called tone units. When an utterance has two focus of information, the stressed syllable will be two. The structure of the tone 
units will ease speakers as they speak. Critically, tonality can minimize ambiguities as the audience receives spoken messages from the written word.

The second intonation system is tonicity, the focus of information related to the placement of the nucleus or tonic syllable, or the structure of the tone unit. While tonality shows the speaker's division of the message into separate pieces of information, tonicity identifies the focus of each piece of information through the placement of the stressed syllable, or it can be called as the nucleus (Tench, 2011). Tonicity is divided into two categories: marked tonicity and unmarked tonicity. In marked tonicity, the tonic can be found anywhere in a clause, while in unmarked tonicity the tonic is positioned at the end of the clause. The researchers did the research using clause because the clause is central processing unit in the lexicogrammar. Different kinds of meanings are mapped into an integrated grammatical structure by clause (Halliday, 2004). Tonicity is the determiner whether or not the information given is new. It is related to the theme-rheme system of textual meaning. Every word that is stressed is called a rheme, and each word with a nucleus is the focus of information that is obtained as new information or rheme.

The tone, also a pitch movement, is the status of information. Tone provides the speaker with choices about the state of each piece of information (Tench, 1996). If we are given a text in writing, there will be various possible ways of intoning it. Chun (2002) divides intonation characteristics into several types, the two main ones being that which reflects the speaker's attitude or feelings and that which the speaker expects the hearer to perceive.

\section{Interpersonal Meaning}

According to Halliday (as cited in Bumela, 2012) there are three types of meaning; ideational meaning, interpersonal meaning, and textual meaning. Halliday, meanwhile, developed four metafunctions, three of which are shown in the clause column (Halliday \& Matthiessen as cited in Nur, 2015).

Table 1

Metafunctions and their reflection in grammar

\begin{tabular}{llll}
\hline Metafunction & Kind of Meaning & $\begin{array}{l}\text { Corresponding } \\
\text { Status of Clause }\end{array}$ & $\begin{array}{l}\text { Favored Type of } \\
\text { Structure }\end{array}$ \\
\hline Experiential & $\begin{array}{l}\text { Constructing a } \\
\text { model of } \\
\text { experience } \\
\text { Enacting social } \\
\text { relationship } \\
\text { Creating relevance } \\
\text { to the context } \\
\text { Constructing a } \\
\text { Textual }\end{array}$ & $\begin{array}{l}\text { Clause as a } \\
\text { representation }\end{array}$ & $\begin{array}{l}\text { Segmental (based } \\
\text { on constituency) }\end{array}$ \\
Logical creation & Clause as a message & Culminative \\
\hline
\end{tabular}


Related to Table 1, the interpersonal meaning is used in this study because it has the closest meaning to intonation, as the structure of interpersonal meaning is formed in the prosodic structure that is interrelated to the intonation. Interpersonal meaning represents the speaker's emotions through the tone in intonation patterns, as well as the addressee's reaction. Interpersonal meaning is closely related to the speaker's interactions in conversation or speech. Although interpersonal meaning is often understood as interacting with other people, in phonology interpersonal meaning is a function of tone (Tench, 2013). It means that interpersonal meaning can be seen from the intonational choices of speakers when they speak.

\section{Methodology}

A qualitative method, more specifically, content analysis, was selected as the design of this research. The content analysis enables researchers to understand human behavior in an indirect way (Fraenkel, 2012). Content analysis was used here because its research object is Sesame Street's puppet show, a television program for children from the United States of America that combines education and entertainment (edutainment). Sesame Street is well known for its puppet characters, created and originally portrayed by Jim Henson and his workshop.

The video of Sesame Street's puppet show season 38 entitled "Alphabet Race" was the primary object in this study and was examined by using the content analysis method. As cited in Ary et al. (2012), content analysis is a research method used to analyze the characteristics of written or visual materials. One episode of Sesame Street's puppet show, entitled "Alphabet Race," was used in this research. The episode was chosen since the episode had no singing and the scenes full with dialogue. The data taken tells about the narrative story in the form of dialogue. The original data air date was on September $28^{\text {th }}, 2007$. This Episode is part of season 38 of Sesame Street's puppet show. The researchers took one episode that represented many characters in one frame who talked to each other, where each character might have their own episodes. This show has an educational goal that is literacy for children. Children typically have the possibility to copy what they have heard. Thus, the educational television program like Sesame Street puppet show has responsibility to make the show qualified, in this case related to intonation. This show plays in 13 minutes and 30 seconds and contained seven scenes in total. The characters involved in "Alphabet Race" episodes were Elmo, El, Sally, Louis, Postman, Scram, Abby, the Woman, Clerk, and Mackena.

The show told that Elmo knows his ABC's so well that he has been chosen to play "The Amazing Alphabet Race," a game show hosted by Amazing El. In order to play, Elmo has to find all the letters of the alphabet before chicken tap dances his way to a gong! Elmo discovers that there are letters all around him! He finds an "A" in "Sesame Street," a "B" in "Bus Stop" and a "C" in "Scram." He heads to Hooper's to look for a "D," "E," and "F," but it's not open. This isn't a problem since Elmo finds some letters he needs in the "Closed" sign on the door. Sally joins in, and they find three "Fs" in "Free Coffee," a "G" on Sally's pogo stick, and an "H" in "Hooper's." Next, they find "J," "K," and "L" in Abby's "Jack and Jill" book. Elmo and Sally continue working against the clock, finding letters in signs around the street. It is not 
until they need "W," "X," "Y," and "Z" that Elmo and Sally notice the ABCDEFGHIJKLMNOPQRSTUVWXYZ delivery man's package which has all the letters they need. They point to the remaining letters just in time and win the game!

The form of the show is the narrative story. Thus there are generic structures of narrative that included in this analysis. The general structures of the narrative are orientation, complication, resolution, and re-orientation. The orientation is located in the first scene that started in 00.00-02.06 minutes. The complication takes place in more than one scene in the show those are from the second scene to the fifth scene. The total duration of complication is from 02.06 minutes to 11.39 minutes. The nest part of the narrative is a resolution. This showplace the resolution in the sixth scene started from a minute of 11.39 to 12.36. Then the last scene is for re-orientation, from 12.36 minutes until the end of the show.

The researchers decided to use the code in this research. The code was taken from the data transcription that the researchers have made. In this research, the researchers provide the code that was adapted from Tench (2011),

(a) |: Intonation unit boundary

(b) Underlining: Tonic syllable

(c) \: Falling tone

(d) / : Rising tone

(e) $\vee \quad$ : Falling-rising tone

(f) $\wedge \quad$ : Rising-falling tone

(g) $(\mathrm{xx}) \quad$ : Indecipherable

The researchers used two kinds of software in doing this research; there are InqScribe and Speech Analyzer. InqScribe helps the researchers in doing transcription. Since the researchers transcribed the video by themselves, InqScribe supported with feature such to play videos and type the transcripts in the same window. Then explorations of three systems of intonation; tonality, tonicity, and tone use speech analyzer software. This is software to analyze the speaker's pitch movement because it is difficult for the researchers to analyze the speaker's patterns of intonation without this system. Some researchers used another software to analyze patterns of intonation, that is PRAAT system, but the researchers decided to use speech analyzer because it is easier, clearer, and faster than the PRAAT system. Chun (2002:119) agreed that computer software could be used to provide precise visualization of intonation patterns. However, before patterns were analyzed, the video was converted into WAV format. The speech analyzer software used can be freely downloaded from http://www01.sil.org/computing/sa/sa download.htm. 


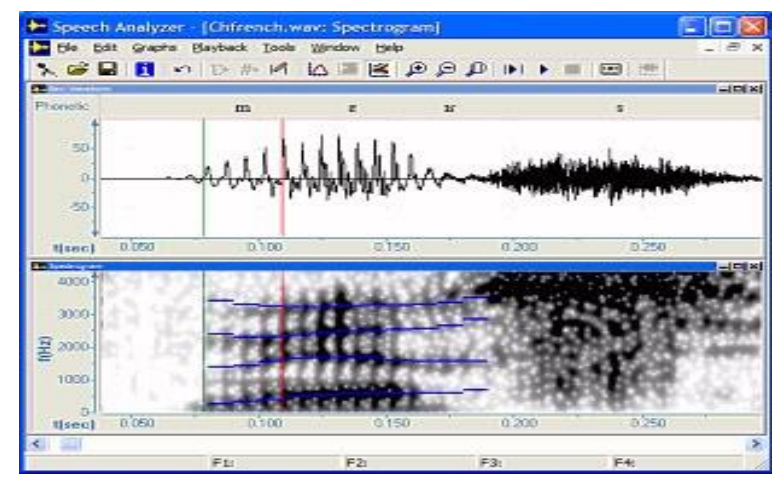

The researchers used version 3.1 of speech analyzer that is the latest version of speech analyzer. There are some minimum system requirements before installing this software (see SIL website for further information). The website also provides a clear explanation about how to use the software. Speech Analyzer is a computer program for acoustic analysis of speech sounds. Speech Analyzer can help to do the following tasks:

1) Perform fundamental frequency, spectrographic, and spectral analysis, and duration measurements.

2) Add phonemic, orthographic, tone, and gloss transcriptions to phonetic transcriptions in an interlinear format.

3) Perform ethnomusicological analysis of music recordings.

4) Use slowed playback, repeat loops, and overlays to assist with perception and mimicry of sounds for language learning.

\section{Results and Discussion}

\section{Intonation Patterns in Sesame Street's Puppet Show}

The intonation patterns used by speakers named Elmo, El, Sally, Louis, Postman, Scram, Abby, the Woman, Clerk, and Mackena on the Sesame Street's puppet show were examined in each scene of the show. This analysis considered several elements related to intonation patterns; namely tonality, tonicity, and tone. According to Tench (2011), these three systems operate in English and are necessary choices in speech. The discussion in this chapter will begin with the tonality, then tonicity, and the last is tone. Tench (2011) revealed that those three elements of intonation have to investigate systematically in the right order, because the investigation of tonicity cannot be done before the investigation of tonality is done, then the investigation of tone cannot be done before investigating the tonicity.

\section{Tonality system.}

The exploration around tonality was started through the clause. The researchers analyze the information by clauses. The clauses divided into two kinds of clauses those are independent clause and a dependent clause. The clause was involved in this research because the clause is the central processing unit in 
lexicogrammar (Halliday, 2004). There is a close relation between intonation and clause. Tench (n.d.), said that intonation operates around the clause because clause and intonation always work alongside it.

Although tonality boundaries typically coincide with clause boundaries, Tench (2011) argued that they do not always do so. This was connected to the markedness of tonality in the show. The markedness tonality divided into neutral and marked. Marked tonality occurs when one clause boundary has more than one unit of information while the neutral tonality means a clause boundary has one unit of information. The number of clauses found in this research was 424 clauses with 169 independent clauses and 255 dependent clauses. In relation to the markedness tonality, the table below shows the neutral and marked tonality found in the show.

Table 2

Markedness of Tonality

\begin{tabular}{cccccc}
\hline No & Scene & Neutral & Percentage & Marked & Percentage \\
\hline 1 & Scene 1 & 35 & $9 \%$ & 17 & $42 \%$ \\
2 & Scene 2 & 63 & $16 \%$ & 2 & $5 \%$ \\
3 & Scene 3 & 80 & $21 \%$ & 10 & $24 \%$ \\
4 & Scene 4 & 88 & $23 \%$ & 2 & $5 \%$ \\
5 & Scene 5 & 78 & $20 \%$ & 2 & $5 \%$ \\
6 & Scene 6 & 15 & $4 \%$ & 3 & $7 \%$ \\
7 & Scene 7 & 24 & $7 \%$ & 5 & $12 \%$ \\
& Total & 383 & $100 \%$ & 41 & $100 \%$ \\
\hline
\end{tabular}

From the results, the first scene, the orientation included a small fraction of neutral tonality and almost half of the marked tonality. The complication is located in four scenes of the show (the second, third, fourth, and fifth). The second scene shows less than a fifth neutral tonality, as well as a small fraction of marked tonality. Meanwhile, the third scene shows $21 \%$ neutral tonality and a small fraction of marked tonality. The fourth scene shows $20 \%$ neutral tonality and only a small fraction of marked tonality. The fifth scene shows a fifth neutral tonality and less than a fifth marked tonality. The next part of the show is the resolution, located in the sixth scene. This scene has a small fraction of neutral tonality as well a small fraction of marked tonality. The last scene represents the re-orientation and includes a small fraction of neutral tonality and less than a fifth marked tonality.

In terms of marked tonality, the most are found in the first scene. Marked tonality represents $42 \%$-almost half-of clauses in the show. The first scene is the opening of the show. Here, marked tonalities are found in the clauses of the opening session. Marked tonality is evidence that more than one unit of information is in a clause. This means that the speaker uses pause and pitch movement to stress more than one piece of information in a clause. 


\section{Tonicity system.}

Tonicity plays a significant role in intonation. Tonicity shows where the prominent syllable is (Tench, 2011). When tonality serves to separate information, tonicity points out the focus of each report carried. The following table shows how the markedness of tonicity was used in the show. The markedness of tonicity is different with the markedness of tonality. The markedness of tonicity deals with the position of the focus of information that is signaled by tonic syllable. The neutral tonicity refers to the tone unit that the tonic is occurred in the final lexical item, whereas the marked tonicity refers to those tone units have tonic that heard in the non-final lexical item.

Table 3

Markedness of Tonicity

\begin{tabular}{cccccc}
\hline No. & Scene & Neutral & Percentage & Marked & Percentage \\
\hline 1 & Scene 1 & 35 & $13 \%$ & 33 & $42 \%$ \\
2 & Scene 2 & 42 & $16 \%$ & 25 & $5 \%$ \\
3 & Scene 3 & 53 & $21 \%$ & 48 & $24 \%$ \\
4 & Scene 4 & 52 & $20 \%$ & 40 & $5 \%$ \\
5 & Scene 5 & 50 & $18 \%$ & 32 & $5 \%$ \\
6 & Scene 6 & 12 & $5 \%$ & 11 & $7 \%$ \\
7 & Scene 7 & 22 & $7 \%$ & 13 & $12 \%$ \\
& Total & 266 & $100 \%$ & 202 & $100 \%$ \\
\hline
\end{tabular}

The tonic syllable or tonicity is found in the last lexical item of an intonation/tone unit. Tone refers to the pitch movement within an intonation unit. Where tonality indicates the unit of information, tonicity indicates the focus of information; the tone shows the status of the information. The findings indicate that the highest neutral tonicity is found in the third scene, part of the complication section of the narrative. This scene has $21 \%$ neutral tonicity. The lowest neutral tonicity is in the sixth scene, part of the resolution of the show. That means that the broad focus of information is located in the complication of the show. The broad focus refers to all the information in an intonation unit being new, whereas narrow focus refers to only part of the information being new.

\section{Tone System.}

Tone refers to pitch movement within an intonation unit. Where a tonality is a unit of information, tonicity indicates the focus of information; as such, tone indicates the status of information. Tench (2011) reveals that tone is the degrees and movement of pitch that occur within the intonation unit. There are four primary systems in tone choices. According to Tench (2011), the fundamental choices of tone are fall $(\backslash)$, rise $(/)$, fall-rise $(\mathrm{V})$ and rise-fall $(/)$. The following table shows the types of tone commonly used by speakers on Sesame Street's puppet show. 
Table 4

Types of Tone

\begin{tabular}{|c|c|c|c|c|c|c|c|c|c|}
\hline No. & Scene & Rise & Percentage & Fall & Percentage & $\begin{array}{l}\text { Rise- } \\
\text { Fall }\end{array}$ & Percentage & $\begin{array}{l}\text { Fall- } \\
\text { Rise }\end{array}$ & Percentage \\
\hline 1 & $\begin{array}{c}\text { Scene } \\
1\end{array}$ & 25 & $32 \%$ & 8 & $12 \%$ & 30 & $12 \%$ & 5 & $6 \%$ \\
\hline 2 & $\begin{array}{c}\text { Scene } \\
2\end{array}$ & 8 & $10 \%$ & 7 & $11 \%$ & 45 & $18 \%$ & 7 & $9 \%$ \\
\hline 3 & $\begin{array}{c}\text { Scene } \\
3\end{array}$ & 21 & $27 \%$ & 19 & $29 \%$ & 46 & $19 \%$ & 15 & $19 \%$ \\
\hline 4 & $\begin{array}{c}\text { Scene } \\
4\end{array}$ & 20 & $26 \%$ & 18 & $28 \%$ & 36 & $15 \%$ & 18 & $23 \%$ \\
\hline 5 & $\begin{array}{c}\text { Scene } \\
5\end{array}$ & 3 & $4 \%$ & 13 & $20 \%$ & 50 & $20 \%$ & 16 & $20 \%$ \\
\hline 6 & $\begin{array}{c}\text { Scene } \\
6\end{array}$ & 0 & $0 \%$ & 0 & $0 \%$ & 13 & $6 \%$ & 10 & $13 \%$ \\
\hline 7 & $\begin{array}{c}\text { Scene } \\
7\end{array}$ & 1 & $1 \%$ & 0 & $0 \%$ & 25 & $10 \%$ & 9 & $10 \%$ \\
\hline \multicolumn{2}{|c|}{ Total } & 78 & $100 \%$ & 65 & $100 \%$ & 245 & $100 \%$ & 80 & $100 \%$ \\
\hline
\end{tabular}

The rise-fall tone was used much more commonly than other types of tone; this tone was used in $52 \%$ of cases, more than half of all units of intonation. Rise and fall-rise tones showed the same percentage of use, representing less than a fifth of all tone usage. The falling tone was the most commonly used tone, representing only $14 \%$ of tone usage.

The rising tone was most prominent in the first scene. Although the rising tone represented less than a third of the 78 intonation units, it was not found in the sixth scene. One in ten rising tones were found in the second scene, while more than a quarter of rising tones were found in the third scene. The fourth scene showed more than a quarter of rising tone usage, while the last scene only had a small fraction of rising tones. The figure and table show that no rising tones were used in the sixth scene.

The falling tone, as the majority, was used in different locations. The falling tone was prominent in the third scene, more than a quarter of all tone units, although no falling tones were found in the last two scenes. In the first scene, there was one in ten falling tones; less than one-fifth of falling tones were in the second scene. The fourth scene showed more than a quarter of falling tones, while the fifth scene showed one fifth falling tones.

The rising-falling tone was most prominent in the fifth scene, which contained 50 of the 244 rising-falling tones in all scenes. The first scene had less 
than a fifth of this type of tone, while the second scene showed less than one-fifth rising-falling tones. Next, almost a fifth of rising-falling tones were found in the third scene, while less than one fifth was located in the fourth scene. The sixth scene only had a small fraction of rising-falling tones. The seventh scene showed one in ten rising-falling tones.

The last type of tone here is the falling-rising tone. The highest percentageroughly a quarter-was found in the fourth scene. The first scene only showed a small fraction of falling-rising tones, the lowest of the type. The second scene shows a small fraction of this type of tone, while the third scene indicates almost a fifth of falling-rising tones. One-fifth of falling-rising tones were located in the fifth scene. Meanwhile, exactly $13 \%$ of falling-rising tones were found in the sixth scene. The last scene contributed one in ten falling-rising tones.

\section{The Construction of Interpersonal Meaning from Intonational Choices in Sesame Street's Puppet Show}

Tench (2011) argues that the primary tone system functions in two dimensions: the speaker's organization of information and the speaker's role in interpersonal meaning. According to McMahon (2002), speakers can use stress and intonation to signal their attitude regarding what they are saying. Furthermore, Cheng et al. (2008) argue that intonation systems are motivated by real-time, specific situations, and decided by speakers to add extra layers of interpersonal meaning to words as they are spoken. Intonation, thus, is closely related to interpersonal meaning.

Here, the researchers presented the data related to the generic structure of a narrative story and highlight some clauses and intonation units to be explained in their relation to interpersonal meaning. The clauses and intonation units here are presented with all three systems in one line. As the show is a narrative in the form of dialogue, the exploration will begin with an orientation, complication, resolution, and re-orientation.

\section{Orientation.}

The orientation of the story "alphabet race" in Sesame Street's puppet show season 38 occurred in the first scene that is the minute $00.00-02.06$. The characters that were involved in the first scene were Clerk and Mackena, Elmo, El, and the Chicken. In this scene, Elmo, Clerk, and Mackena have known each other, but El was a new person for them. El came to give Elmo a game that was the alphabet race game. Several clauses have been used here to analyze interpersonal meaning in orientation part (see Appendix). The researchers looked at the beginning of the first scene, the orientation of the story. The researchers also examined the tone units that represented four types of tones used by speakers. Elmo, in this scene, speaks with El in eight clauses but uses nine intonation units. In clause two and three, Elmo says greeting to Mackena, using a rising tone. The rising tone of the greeting indicates that Elmo is being friendly and considering the addressees' feelings. According to Tench (2011), Dominance in social interaction is the expression of the speaker's feelings and is signaled by a fall while deference is a 
consideration of the addressee's feelings and is signaled by a rise. In clauses 9, 10, and 11, Elmo uses the rising tone that marks a general question. In clause 12, Elmo seems surprised with the coming of El and uses the rise-fall tone. El then talks to Elmo, as in the sixth clause. This is a command because El led the game, and El uses the rise-fall intonation; the interpersonal meaning that can be drawn by that intonation pattern is that El will not allow the other person to decide whether or not to act. The impression is that El is compelling Elmo to get ready and learn the alphabet. In clause 13, El is being impressed by Elmo, expressed through the fall-rise tone. However, in the next clause, El takes a falling tone, which communicates that he is uttering a final statement.

\section{Complication.}

The complication of this story occurred in four scenes: the second, third, fourth, and fifth scenes. The third scene was in the 02.06-03.37 minutes. The third scene occurred in the 03.37-06.13 minutes. Then the fourth scene was in the 06.1309.24 minutes. And then the fifth scene was in the 09.24-11.39 minutes. The complication here presents the conflict within the story. The researchers provide further information about the interpersonal meaning used by the speakers from the second scene (see Appendix). In the second scene, Elmo speaks with Louis, his neighbour, and asks him about a game he is playing. In clause 54, there is one intonation unit, using marked tonicity and rise-fall tone. Here Elmo speaks with the hope of finding the letters of the alphabet, which is seen from the social interaction of Elmo and Louis. Louis comes and greets Elmo, using the rise-fall tone. In this case, the rise-fall tone in the greeting means that the speaker's feelings dominate and that the talks are formal. It also means that Louis is impressed by Elmo. Elmo asks Louis using a fall-rise tone, meaning that Elmo wants to know the information and wants Louis to tell him. Elmo repeats the question with a rise-fall tone in clause 64, which indicates Elmo's desire to ensure that his question is clear and that Louis understands his question. Dominant in this scene is the rise-fall tone, which conveys "impression".

\section{Resolution.}

The resolution of the narrative is from the sixth scene, precisely in 11.3912.36 minutes, in which Elmo and Sally find all letters of the alphabet before the chicken hits the gong. Here, Elmo and Sally appear very happy, with no apparent anger. The expression of excitement is seen from the intonational choices (see Appendix). In the resolution part, precisely in the sixth scene, the researchers take the conversation between Elmo and Sally. There, Elmo delivered five units of intonation with the various markedness of tonicity. Elmo provided command and statements in his talks. The command is seen in clause 390, but in the rising tone, the command usually uses falling-rising tone, thus clause 390 categorized into a warning. Elmo still allows the addressee to decide to go or stay with him. Then, Elmo continued his talk with a statement with both fall - rise and rise-fall tone. Elmo knew something, and he wanted other people (Sally) to know what he knows. Sally's 
responds with a rising tone indicate that he is happy to hear the information from Elmo, and he is so excited.

\section{Re-Orientation.}

The last discussion is in the re-orientation part that occurred in the seventh scene. It was in the minutes 12.26-13.50. In the orientation part of the story and El gives a prize to Elmo and Sally for winning the game. Intonation patterns found in the intonation units of the clauses in the re-orientation express various interpersonal meanings. El states his message with intonation using a falling tone, which indicates that the speaker knows and wants to say something. The tone could be noticed by seeing the interaction as well. In this case, El knows that Elmo has won the game and tries to explain to Elmo that he has the right to receive the prize. Elmo shows a feeling of surprised, marked by the rise-fall tone in clause 410 (see Appendix).

\section{Conclusions}

Based on the results and discussion above, a total of 424 clauses are used by speakers for the episode. Of these 424 clauses, the speaker conveys more than that, because one clause can have more than one unit of information (tone unit); a total of 468 tone units were found, as several clauses have more than one tone unit. Of these, the researchers identified both neutral and marked tonalities, with 383 of the former and 41 of the latter. Speakers focused on two types of information-broad focus information and narrow focus information-as seen from the location of the nucleus or stressed syllable. The focus of information is seen in every single tone unit that is separated from clauses in tonality. The broad and narrow focus of information determines the markedness of tonicity. In this episode, the researchers found 267 neutral tonicities and 201 marked tonicities. Neutral tonicity was thus more substantial in number than marked tonicity; this means that the speakers focused primarily on broad focus information.

The tone system can be analyzed when tonality and tonicity are considered. From the location of the nucleus or position of prominence in the clause, the tone is the matter how the speaker stresses the distinction. Four types of tone were found in the show: rise, fall, fall-rise, and rise-fall. The highest percentage was rise-fall tones, representing 245 tone units or $52 \%$ of all tone units. The most uncommon type of tone was the falling tone, representing 65 tone units or only $14 \%$ of all tone units in the episode.

Interpersonal meaning expresses the speaker's emotions and is also related to the speaker's attitude. Interpersonal meaning in this research was identified from a strict phonology perspective, as seen from speakers' intonational choices. The researchers considered the interpersonal meaning of each speaker when choosing specific intonation patterns. It can be concluded that the speakers' intonation patterns were interrelated with the three primary systems of intonation. When people talk, they have the information that they wanted to convey, the focus of 
information, and the status of information. Thus, people always speak using three primary systems of intonation that draw intonation patterns.

On the other hand, intonation patterns also undoubtedly convey the interpersonal meaning of the speaker. The paper has beneficial implications for language teaching and learning and can provide a good model for students and teachers to study intonation. Sesame Street puppet show drew clear example for children to utter the conversation with interpersonal meaning in each dialogue. With this, they can notice how an utterance deals with intonation. As such, it will be very beneficial for them to study intonation. Teachers will be more readily able to teach intonation to their students.

\section{References}

Ali, F., \& Yunus, M. M., (2014). Language learning strategies used by the gifted students in enhancing their proficiency in speaking English. In proceedings of the International Conference on Gifted and Talented Education (pp. 97-105). Selangor, Malaysia: Universiti Kebangsaan Malaysia.

Ary, D., Jacobs, L., Razavieh, A., \& Sorensen, C. (2012). Introduction to research in education. Belmont, TN: Thomson Wadsworth.

Bumela, L., (2012). The metafunction revealed: EFL learners' experience in making sense of the text. Indonesian Journal of Applied Linguistics, 1(2), 106-119.

Cheng, W., Greaves, C., \& Warren, M. (2008). A corpus-driven study of discourse intonation. Amsterdam, Netherlands: John Benjamins.

Chun, D. M., (2002). Discourse intonation in L2: from theory and research to practice. Amsterdam, Netherlands: John Benjamins.

Kuhlen, E., (2004). Prosody in conversation: Studies in interactional sociolinguistics. Cambridge, UK: Cambridge University Press.

Cresswell, J. W., (2009). Research design: qualitative, quantitative, and mixed methods approach. London, UK: Sage Publications.

Demirci, K., (2011). On the importance of the phoneme theory. International Periodical for the Languages, Literature, and History of Turkish or Turkic, 6(2), 259-366.

Fraenkel, J. R., Wallen, N. E., \& Hyun, H. H. (2012). How to design and evaluate research in education. New York, NY: McGraw-Hill.

Halliday, M. A., K. (1985). Spoken and written language. Oxford, UK: Oxford University Press.

Halliday, M. A., K. (1994). An introduction to functional grammar. London, UK: Horder Arnold.

Halliday, M. A. K., Matthiessen, C. M. M. (2004). An introduction of functional grammar. New York, NY: Oxford University Press.

Hughes, R., (2011). Teaching and researching speaking. London, UK: Pearson Education.

Kula, N. C., Bortma, B., \& Nusukawa, K. (2010). Continuum companion to English phonology. New York, NY: Continuum International Publishing Group. 
Liu, Y. L. (2008). The effectiveness of interactive instruction on the intonation learning of Chinese college learners. Cross-cultural Communication, 4(1), 90103.

Nur, S., (2015). Analysis of personal meta-function in public speeches: A case study of Nelson Mandela's presidential inauguration speech. The International Journal of Social Sciences, 30(1), 52-63.

Oladipupo, R. O. (2010). The Intonation of Noun Phrase Subjects and ClauseModifying Adverbials in Nigerian English. African Research Review, 4(3).

Onsuwan, C., Tantibundhit, C., Saimai, T., Saimai, N., Chootrakool, P., \& Thatphithakkul, S. (2012). Analysis of Thai tonal identification in noise. In the Proceedings of 14th Australasian International Conference on Speech Science and Technology.

Puga, K., Fuchs, R., Setter, J., \& Mok, P. (2017). The perception of English intonation patterns by German L2 speakers of English. Interspeech. Retrieved from https://doi.org/10.21437/Interspeech.20171279

Tench, P. (n.d.). A systemic-functional model of the intonation of clauses in English. Wales: Cardiff University.

Tench, P., (2011). Transcribing the sound of English: a phonetics workbook for words and discourse. New York, NY: Cambridge University Press.

Tuan, I. T. (2012). Further glimpse at intonation teaching. Asian Social Science, 8(1), 224-235. 


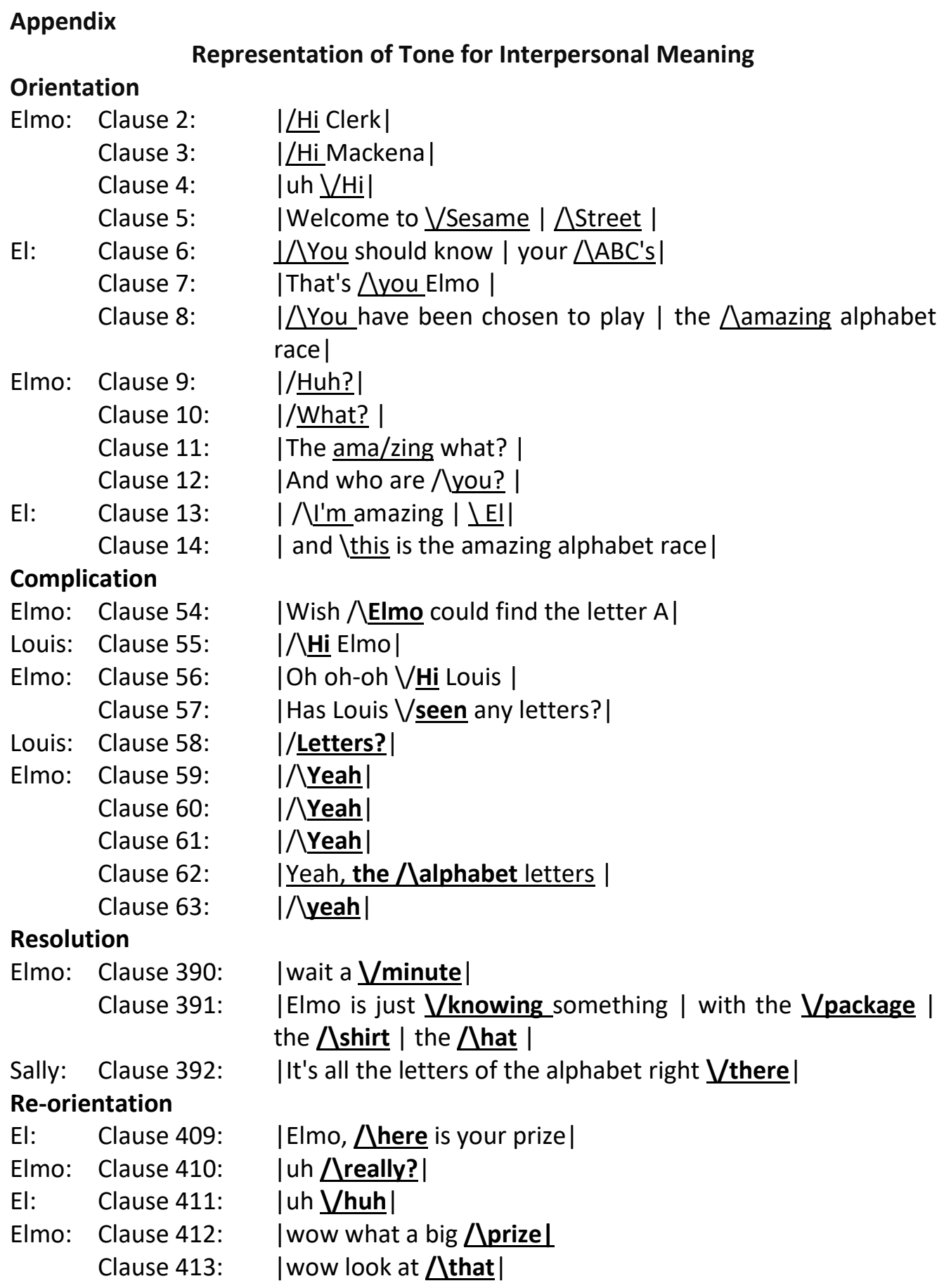

